\title{
THE LATERAL FLOW CARD TEST: AN ALTERNATIVE METHOD FOR THE DETECTION OF TRICHINELLA INFECTION IN SWINE
}

\author{
PATRASCU I. ${ }^{1}$, GAMBLE H.R. ${ }^{2}$, SOFRONIC-MILOSAVLJEVIC L. ${ }^{3}$, RADULESCU R. ${ }^{4}$, ANDREI A. ${ }^{4}$, IONESCU V. ${ }^{4}$, \\ TIMOCEANU V.5, BOIREAU P. ${ }^{6}$, CUPERLOVIC K. ${ }^{3}$, DJORDJEVIC M. ${ }^{7}$, MURRELL K.D. ${ }^{8}$, \\ NOECKLER K. 9 \& POZIO E. ${ }^{10}$
}

\begin{abstract}
Summary :
A novel lateral flow card (TS-Card pork) test was developed for the serological detection of Trichinella infected pigs. Based on extensive studies performed in Romania during 1999-2000 this test proved to be highly specific, sensitive, rapid (3-12 minutes) and easy to use (no need for laboratory facilities). It can be used both for the detection of Trichinella infection in carcasses and for epizootiological studies using a variety of samples including whole or dried blood, serum, or tissue fluids. The TS-Card pork test, used as a screening test, can be the foundation of an on-farm or field based inspection system to significantly improve food safety in countries with a high prevalence of Trichinella in pigs or other food animal species. The results presented are also promising for application of the test in an on-line laboratory based inspection system since the speed of the test allows sufficient time to rail out suspected hog carcasses during the slaughter process.
\end{abstract}

KEY WORDS : serology, Trichinella

Ir VD Research Laboratories, USA and A.R.T.E. SRL, Romania developed a novel, simple and rapid TSCard pork lateral flow test for detection of Trichinella infection in swine. A field evaluation of the TSCard pork test was performed in an extensive, double blind study in Romania. The focus of the study was comparison of two diagnostic methods, the TS-Card pork (a serological method) and trichinoscopy (a parasitological method), in their efficiency for the routine control of trichinellosis in pigs. The presence of Trichinella infection in the pork was verified using the artificial digestion method. The results are presented in this communication.

1 A.R.T.E. International SRL, Pascal Cristian 33, 77713 Bucharest, Romania, Tel.: (401)312 1254, 3125064 -Fax: (401) 3125643. e-mail: arte-med@cabletv.ro

${ }^{2}$ USDA, Parasite Biology and Epidemiology Laboratory, Beltsville, MD 20705, USA.

${ }^{3}$ Institute for the Application of Nuclear Energy (INEP), Belgrade, Yugoslavia.

${ }^{4}$ Institute for Diagnosis and Animal Health, Ministry of Agriculture and Food National Sanitary Vetiranary Agency (IDSA), Bucharest, Romania.

${ }^{5}$ Directia Sanitara Veterinara (DSV), Timisoara, Romania

${ }^{6}$ UMR, BIPAR, Maisons-Alfort Cedex, France.

${ }^{7}$ Institute of Meat Hygiene and Technology, Belgrade, Yugoslavia

${ }^{8}$ USDA, Agricultural Research Service, Beltsville, MD 20705, USA.

${ }^{9} \mathrm{BgVV}$, Berlin, Germany.

${ }^{10}$ Istituto Superiore di Sanità, Rome, Italy.

\section{MATERIALS AND METHODS}

SWINE

$\Lambda$ total of 1,098 animals from the Timis, Prahova and Teleorman districts of Romania were originated fred in this study. Of this group, 635 pigs originated from Trichinella non-endemic farms (Timis and Teleorman districts) and 463 pigs originated from Trichinella endemic farms (Prahova district; prevalence of Trichinella infection in pigs reported to be over $20 \%$ in the last three years).

\section{BLOOD AND SERUM SAMPLES}

Whole blood and serum samples were collected from all pigs examined in the study. Blood samples were collected in EDTA coated tubes while blood for serum was collected in non-coated tubes. All samples were labeled according to the protocol.

\section{MEAT SAMPLES}

A sample of diaphragm pillar (crus) tissue was collected for trichinoscopy and for pooled or individual peptic digestion testing.

\section{PROTOCOL FOR THE DOUBLE BLIND STUDY}

The blood, serum and meat samples used for the double blind studies were identified by tag number and recording number. Samples were tested by recording number and were identified by tag number after trichinoscopy, TS Card pork test, and peptic digestion assay. The Romanian Ministry of Agriculture conducted this project through the National Sanitary Veterinary Agency and the Institute for Diagnosis and Animal Health, Bucharest, Romania. A Romanian official, representing the independent State Institutions signed the final report as proof that the study was performed as a double blind.

\section{TRICHINOSCOPY METHOD}

Trichinoscopy was done according to European Economic Community Commission Directive 84/319/EEC 


\begin{tabular}{lccc}
\hline \multicolumn{1}{c}{ Animals examined from } & $\begin{array}{c}\text { Ts-Card pork } \\
\text { positive/tested (\%) }\end{array}$ & $\begin{array}{c}\text { Trichinoscopy } \\
\text { positive/tested (\%) }\end{array}$ & $\begin{array}{c}\text { Peptic digestion } \\
\text { positive/tested (\%) }\end{array}$ \\
\hline Trichinella non-endemic farms & $3 / 635(0.47)$ & $0 / 635(0)$ & $0 / 635(0)$ \\
Trichinella endemic farms & $93 / 463(20.09)$ & $60 / 463(12.96)$ & $93 / 463(20.09)$ \\
$\quad$ Total & $96 / 1098(8.74)$ & $60 / 1098(5.45)$ & $93 / 1098(8.47)$ \\
\hline
\end{tabular}

Table I. - Comparative efficacy of serological (TS-Card pork) and direct parasitological methods for the detection of Trichinella infection in pigs in Romania.

and the OIE Manual of Standards for Diagnostic Tests and Vaccines (2000). The 28 fields of one compressorium were examined for each sample.

\section{PEPTIC DIGESTION METHOD}

This method was performed as described in OIE Manual of Standards for Diagnostic Tests and Vaccines (2000), Chapter 3.5.3.

\section{IDENTIFICATION OF THE TRICHINELLA GENOTYPE}

The Instituto Superiore di Sanita, Rome, Italy, conducted the genotype analyses of infective Trichinella muscle larvae as previously described (Pozio et al., 1997).

\section{TS-CARD PORK LATERAL FLOW TEST}

This test was performed according to the manufacturer's instructions (IVD Research Laboratories, USA and A.R.T.E. SRL, Romania).

\section{ANTIBODY DETECTION}

ELISA (Gamble, 1998) and Western blot (Laemmli, 1970; Towbin et al., 1979) analyses, using ES antigen and anti-swine-HRP, were performed simultaneously at INEP (Belgrade, Yu) and ISS (Rome, Italy).

\section{RESULTS}

T The results obtained for the comparative analyses of the efficacy of the serological (TS-Card pork) and direct parasitological methods for detection of Trichinella infections in pigs in Romania are presented in Table I.

If two bands were visible, the sample was positive; if there was only one band (control band) the test was negative. The test took from three minutes (for the appearance of a specific band with very strong positive sera) up to 12 minutes (for very weak positive sera).

Using the TS-Card pork test, 632 sera were identified as negative and three sera $(0.47 \%)$ as positive. Using two other serological tests, ELISA and Western blot,

\begin{tabular}{lcc}
\hline $\begin{array}{c}\text { Results of tests performed } \\
\text { for determination } \\
\text { of Trichinella } \text { infection in pigs }\end{array}$ & No. & \% \\
\hline Positive Trichinoscopy/Positive TS-Card & $60 / 93$ & 64.52 \\
Negative Trichinoscopy/Positive TS-Card & $33 / 93$ & 35.48 \\
Positive Trichinoscopy/Negative TS-Card & 0 & 0 \\
Negative Trichinoscopy/Negative TS-Card & 0 & 0 \\
\hline
\end{tabular}

Table II. - Comparative analyses of results obtained by TS-Card pork and trichinoscopy in pigs that were positive by peptic digestion.

specific antibodies against Trichinella were not seen in any of the 635 samples. All 635 animals were negative by trichinoscopy and by peptic digestion (as a confirmatory assay). Based on these results, the three pigs testing positive by TS-Card pork were considered to be false positives. Results obtained with the TS-Card pork test on 463 pigs from Trichinella endemic farms revealed that $93(20.09 \%)$ animals were seropositive. A significant discrepancy was seen in positive results obtained by trichinoscopy (12.96\%) and peptic digestion $(20.09 \%)$. Using the TS-Card pork test, there were no false positive or false negative results on swine originating from Trichinella endemic farms when compared with results of peptic digestion.

Results comparing the efficiency of the TS-Card pork test and trichinoscopy for the routine control of trichinellosis are presented in Table II.

Trichinoscopy identified only $60(64.52 \%)$ of the 93 pigs that were positive by peptic digestion. At the same time, the TS-Card pork test identified all infected animals. Peptic digestion analyses pointed out that in Trichinella endemic regions in Romania the infectivity level was variable with worm burdens ranging from $0.1 \mathrm{LPG}$ to $44 \mathrm{LPG}$. Of the larvae recovered from pigs, it was determined that most isolates were whether T. spiralis and T. britovi.

Additional results obtained by TS-Card pork on all analyzed animals showed that there were no discrepancies in two or more analyses of one serum or blood sample originating from the same pig, as well as between results obtained using either serum or blood from the same pig (100\% compatibility on sera and blood results by TS-Card pork; $100 \%$ test reproducibility). 


\section{DISCUSSION}

T $\mathrm{n}$ this study it was established that even very low level infections with Trichinella (0.1 LPG of mus1 cle), can be detected using the TS-Card pork test. Study of the applicability of the TS-Card pork test for the detection of pig infections in Trichinella endemic regions, points out that the test is very specific because of the absence of either false negative or false positive results. The results obtained demonstrating a very low rate of false positive, results in swine from nonendemic regions of Romania should be examined further. Additional research will be need to establish methods for evaluating weak and strong bands on TS cards. In fact, preliminary results suggest that the appearance of bands with different intensity is confusing for the reader (Pozio E., unpublished data). Furthermore, the sensitivity of the TS-card test in the window period (i.e., from 15 and 21 days after infection when larvae of $T$. spiralis can infect a new host, but serological tests could be negative) should be evaluated. The reproducibility of the TS-Card pork test is very high.

The TS-Card pork test is very easy to perform. No equipment is needed and it can be performed in the field, in small veterinary clinics or virtually anywhere else. The results obtained can be saved for confirmation.

Based on the favorable results obtained in this study, the TS-Card pork test has a variety of potential uses. It can be used for identifying infected animals and dealing with them on an individual basis or it can be used for epizootiological studies. It is a tool that could be used by slaughterhouses to test animals that are suspected to originate from farms with endemic trichinellosis, with the aim of reducing expenses of buying, slaughtering and discharging meat of infected animals or as a method to rapidly identify individually infected animals when positive results are obtained by pooled digestion (thus reducing time and expense due to the long procedure of digestion re-examination).

\section{REFERENCES}

European Economic Community. Commission Directive 84/319/EEC. Official Journal of the European Communities, 1984, 167, 34-43.

Office International Des Epizooties, World Organization for Animal Health, Manual of Standards for Diagnostic Tests and Vaccines, 2000. Chapter 3.5.3., Trichinellosis, 1-5.

Pozio E., Tamburrini A., Sacchi L., Gomez Morales M.A., Corona S., Goffredo E., \& La Rosa G. Detection of Trichinella spiralis in a horse during routine examination in Italy. International Journal for Parasitology, 1997, 27, $1613-1621$.
GAMBLE H.R. Sensitivity of artificial digestion and enzyme immunoassay methods of inspection for trichinae in pigs. Journal of Food Protection, 1998, 61 (3), 339-343.

LAEMmLi U.K. Cleavagae of structural proteins during the assembly of the head of bacteriophage T4. Nature, 1970 $227,680-685$.

Towbin H.T., Staehelen T. \& Gordon J. Electrophoretic transfer of proteins from polyacrilamyde gels to nitrocellulose sheets: procedure and some applications. Proceedings of National Academy of Sciences U.S.A., 1979, 76, 4350-4354. 